\title{
Sludge settling characterization for the mathematical modelling of sidestream treatment processes
}

\author{
Piotr Balbierz ${ }^{1, *}$, and Katarzyna Rucka $^{1}$ \\ ${ }^{1}$ Wroclaw University of Science and Technology, Faculty of Environmental Engineering, Wybrzeze \\ Wyspianskiego 27, 50-370 Wroclaw, Poland
}

\begin{abstract}
More stringent effluent limits, especially with regard to total nitrogen, force wastewater treatment plants to consider sidestream nitrogen removal from digested sludge dewatering liquor which can contain up to $20 \%$ of incoming nitrogen load. Deammonification, the most promising biological technology for sidestream nitrogen removal, is based on partial short-cut nitrification and the Anammox process. Both steps of this process are conducted by slowly growing autotrophic bacteria, namely nitrifies and Anammox, which however may form different types of sludge: flocculent and granular, respectively. Nevertheless, ensuring effective sludge separation from treated effluent is crucial for the ability to retain both kinds of slowly growing biomass in the system. This paper presents the principles of sludge settling modelling, the results of a series of column tests conducted on sludge from pilot-scale two-stage deammonification treatment facility, as well as an attempt to estimate settling parameters in order to fit a sedimentation model.
\end{abstract}

\section{Introduction}

Sedimentation is a gravitational solids-liquid separation, based on the differences in density between solid particles and the liquid. In conventional suspended-growth activated sludge systems, sedimentation is one of the most crucial physical unit operations, as it directly affects the quality of the treated effluent [1].

Secondary clarifiers are designed to achieve two goals which are critical to operation and performance of activated sludge system: clarification of the final effluent to comply with the discharge limits and thickening of the sludge to minimize the stream recirculated to bioreactors. Both settler functions are dependent on sludge settling properties, which tend to be highly variable and difficult to predict. Therefore, poor biomass separation is not uncommon, which may lead to severe biological process disturbances [2].

Depending on the concentration and properties of solid particles four types of settling behaviour can be distinguished at different layers along the height of primary and secondary settling tanks, which are discrete particle settling, flocculent particle settling, hindered settling and compression settling [1].

* Corresponding author: piotr.balbierz@pwr.edu.pl 


\subsection{Sedimentation in sidestream treatment processes}

More stringent effluent limits, especially with regard to total nitrogen, force wastewater treatment plants to consider sidestream nitrogen removal from digested sludge dewatering liquor which can contain up to $20 \%$ of incoming nitrogen load.

Deammonification, the most innovative and promising biological technology for sidestream nitrogen removal, is based on partial short-cut nitrification and the anammox process (short for ANaerobic AMMonium OXidation). In the partial nitrification step approximately half of the initial ammonium is oxidized to nitrite by strictly aerobic ammonium oxidizing bacteria. In the anammox step ammonium (electron donor) and nitrite (electron acceptor) are converted by strictly anaerobic anammox bacteria into dinitrogen gas and small amounts $(\sim 10 \%)$ of nitrate without external organic carbon source. Therefore, deammonification allows to decrease oxygen demand by $60 \%$, and organic carbon demand and sludge production by $90 \%$, compared to conventional nitrification/denitrification systems [3, 4].

Due to lower investment costs, deammonification is usually operated in one-stage systems, where both steps with different requirements take place in one reactor, which makes the process control more complicated. An alternative are two-stage systems, where partial nitritation and anammox are split in two reactors in series, which allows to optimize process condition for each of the steps separately. Moreover both attached-growth (biofilm, moving bed biofilm reactor and rotating biological contactor) and suspended growth (sequencing batch reactor and upflow anaerobic sludge blanket reactor) systems are in operation at full-scale [4].

Partial nitritation and anammox are conducted by slowly growing autotrophic bacteria with a long doubling time, which, however, in the suspended-growth systems may form different types of sludge: flocculent and granular, respectively. In favourable conditions (short settling time and adequate shear force) can grow forming dense, well settling granules, which can settle with velocities over $100 \mathrm{~m} / \mathrm{h}$, compared with $1-10 \mathrm{~m} / \mathrm{h}$ for flocculent sludge $[5,6]$.

Nevertheless, ensuring effective sludge separation from treated effluent is crucial for the ability to retain both kinds of slowly growing biomass in the system, especially because solids retention, settling and separation is among the most common operating problems in full-scale deammonification installations [4].

\subsection{Sedimentation modelling}

Mathematical description of activated sludge sedimentation is usually based on the solids flux theory, which states that sludge movement in the thickening zone of the settler results from gravity settling and convection due to sludge recirculation underflow stream. The solids flux caused by gravity settling is a function of sludge concentration and sludge zone settling velocity (ZSV), which characterizes hindered settling. ZSV is dependent on the sludge concentration and expressed by the classic Vesilind equation [3]:

$$
v_{s}=v_{0} e^{-k X}
$$

where $v_{s}$ is sludge settling velocity, $v_{0}$ is maximum sludge settling velocity, $X$ is sludge concentration and $k$ is empirical settling parameter.

However, it should be noted that Vesilind equation is valid for the hindered settling only, as, when the sludge concentration goes to zero, the predicted settling velocity reach values, which are not realistic. Therefore, Takacs et al. [7] presented a modification of 
Vesilind equation, which accounts for the fact that settling velocity decreases when sludge concentration approaches zero, and is expressed by the following set of equations:

$$
\begin{gathered}
v_{s}=v_{0}\left(e^{-r_{h}\left(X-X_{\min }\right)}-e^{-r_{f}\left(X-X_{\min }\right)}\right) \\
X_{\min }=f_{n s} X_{0} \\
0 \leq v_{s} \leq v_{0, \max }
\end{gathered}
$$

where $r_{h}$ is hindered zone settling parameter, $r_{f}$ is flocculent zone settling parameter, $X_{\min }$ is minimum attainable suspended solids concentration, $X_{0}$ is mixed liquor suspended solids entering the settler, $f_{n s}$ is non-settleable fraction of mixed liquor suspended solids and $v_{0, \max }$ is an upper limit of sludge settling velocity.

The traditional models describing activated sludge settling velocity are no longer valid for granular sludge, therefore some theoretical models based on the Stock or Allen equations have been proposed [8,9]. However, they require the knowledge about such parameters as granule diameter, density, sphericity and mass shape factor that are usually not readily available.

On the other hand Liu et al. [10] proposed a Vesilind-based generalized model for settling velocity of aerobic and anaerobic granular sludge, which is a function of mean size of granules $\left(d_{p}\right)$, sludge volume index $(S V I)$, and sludge concentration $(X)$ :

$$
v_{s}=\alpha \frac{d_{p}^{2}}{S V I} e^{-\beta X}
$$

where $\alpha$ and $\beta$ are constant coefficients. For small enough particles model reduces to the classic Vesilind equation.

The aim of this paper is to characterize and compare settling properties of activated sludge, from a full-scale biological nutrient removal plant and two-stage deammonification pilot-scale plant, based on the results of a series of column tests, as well as to attempt to estimate settling parameters in order to fit a sedimentation model.

\section{Materials and methods}

This study was conducted at the pilot plant used for assessment of different reject water treatment processes, equipped with four $150 \mathrm{dm}^{3}$ SBR-type reactors and fed with real reject water from full-scale sludge dewatering station at Wroclaw WWTP in south-west Poland.

\subsection{Source of sludge}

Three different kinds of activated sludge were used in the experiment.

First sludge sample (BNR) was taken from a full-scale biological nutrient removal Wrocław WWTP (approx. 1000000 p.e.) operated in winter conditions $\left(10^{\circ} \mathrm{C}\right)$ at a long solids retention time (SRT) of $35 \mathrm{~d}$ and mixed liquor suspended solids (MLSS) of $5.5 \mathrm{~kg} \mathrm{TSS} / \mathrm{m}^{3}$.

The second sludge sample (SNC) was taken from a pilot-scale short-cut nitrification SBR fed with real sludge dewatering reject water and operated at temperature of $25^{\circ} \mathrm{C}$, an SRT of $3 \mathrm{~d}$ and MLSS of $1.5 \mathrm{~kg} \mathrm{TSS} / \mathrm{m}^{3}$. At start-up this SBR was seeded with the BNR 
sludge, and during later stable 6 month operation a daily dose of BNR sludge was added to keep the desired sludge concentration and improve settling properties.

The last sludge sample (ANX) was taken from a pilot-scale Anammox SBR fed with partially nitrified real sludge dewatering reject water and operated at temperature of $23^{\circ} \mathrm{C}$, an SRT of $50 \mathrm{~d}$ and MLSS of $2.0 \mathrm{~kg} \mathrm{TSS} / \mathrm{m}^{3}$. At start-up this SBR was seeded with granular sludge from an UASB Anammox reactor, without further addition during stable 6 months operation.

\subsection{Batch settling test procedure}

In order to characterize settling properties of sludge samples and to determine zone settling velocity as a function of sludge concentration a series of batch settling tests was carried out. Batch settling test are considered to be a good source of data for estimation of the sedimentation model parameters as the obtained result depend only on the physical properties of the settling column (which are constant for a given set-up) and the settling properties of the sludge [11].

Each sludge sample was thickened for an hour to achieve initial concentration of approximately $9 \mathrm{~kg} \mathrm{TSS} / \mathrm{m}^{3}$. From this thickened sample a series of samples with more or less equidistant sludge concentrations was prepared by diluting the sludge with an appropriate effluent. The range of concentrations was chosen to ensure that sufficient settling velocity and a distinct sludge/water interface could be observed.

Batch settling tests were performed at room temperature (approx. $22^{\circ} \mathrm{C}$ ) in settling columns with a height of $50 \mathrm{~cm}$ and diameter of $8 \mathrm{~cm}$ without a stirrer (Fig. 1.), by pouring a well-mixed sample into a column and recording the height of sludge blanket for a period of 20-60 minutes depending on the concentration with the recording interval varied from $20 \mathrm{~s}$ to $5 \mathrm{~min}$.

For each test the recorded interface height was plotted against time, and the settling velocity was determined from the slope of the linear part of curve.

The sludge concentration was determined after each test according to EN-872 - standard direct method for suspended solids on glass fibre filters with $1.2 \mathrm{~m}$ pore size.

The obtained relationship between settling velocity and sludge concentration was used to estimate parameters of the Takacs sedimentation model [7], as it does not require the knowledge of sludge morphology and is commonly used in commercially available simulators.

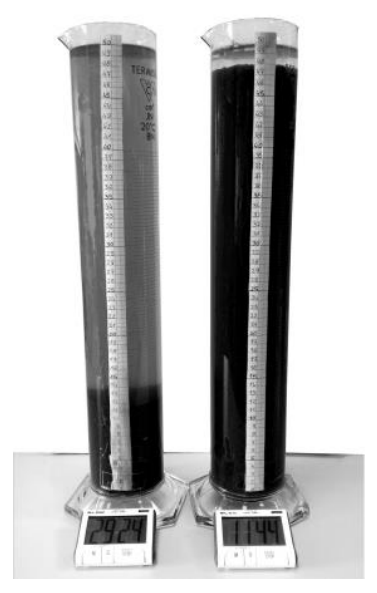

Fig. 1. Experimental set-up. 


\section{Results and discussion}

The results of the batch settling test series with different ANX sludge concentration presented as the change of sludge blanket height in time are show in Fig. 2. As the time in which the linear part of the curve is observed varies significantly with sludge concentration, it is important to carefully choose the test length and recording interval to obtain reliable data.

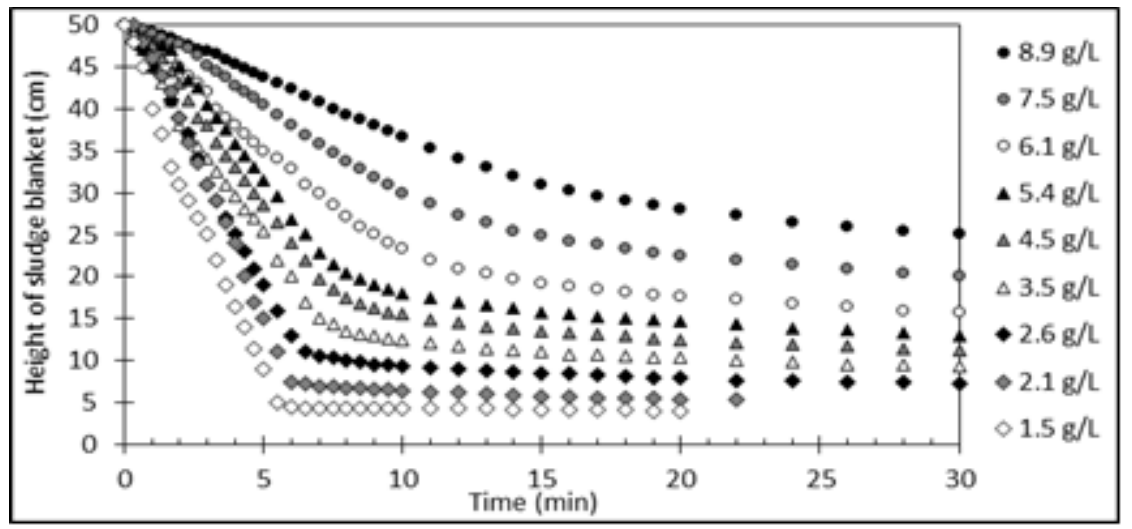

Fig. 2. Measured sludge blanket height in time from the test series with ANX sludge.

The comparison of determined zone settling velocities as a function of the BNR, SCN and ANX sludge concentration is presented in Figure 3. The settling velocities for the BNR sludge $\left(1.6-6.3 \mathrm{~kg} / \mathrm{m}^{3}\right)$ were in range of $0.04-5.6 \mathrm{~m} / \mathrm{h}$, for the SCN sludge $\left(1.4-5.3 \mathrm{~kg} / \mathrm{m}^{3}\right)$ $0.66-5.5 \mathrm{~m} / \mathrm{h}$ and for the ANX sludge $\left(1.5-8.9 \mathrm{~kg} / \mathrm{m}^{3}\right) 0.89-4.85 \mathrm{~m} / \mathrm{h}$, and fall in the standard range for the flocculent sludge $1-10 \mathrm{~m} / \mathrm{h}[5,6]$. The BNR and SCN sludge showed similar characteristics at low concentration, but in case of the BNR sludge a rapid decrease of settling velocity above $3.5 \mathrm{~kg} / \mathrm{m}^{3}$ was observed, which is a known phenomenon at labscale due to elevated wall friction effect and can be mitigated by introduction of slow stirring (1-2 rpm) [12]. The ANX sludge showed more flat characteristics, and generally significantly higher sedimentation velocities, especially at higher concentrations.

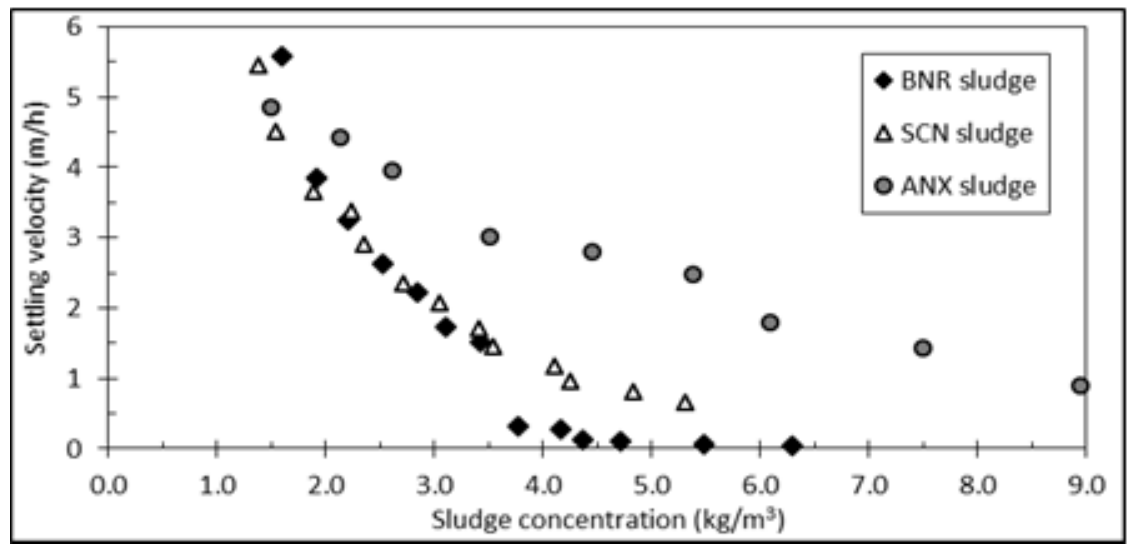

Fig. 3. Comparison of determined settling velocities for BNR, SCN and ANX sludge.

The best fit of the Takacs sedimentation model to the experimentally determined zone settling velocities for the BNR, SCN and ANX sludge is presented in Figure 4, and the estimated model parameters are listed in Table 1. 

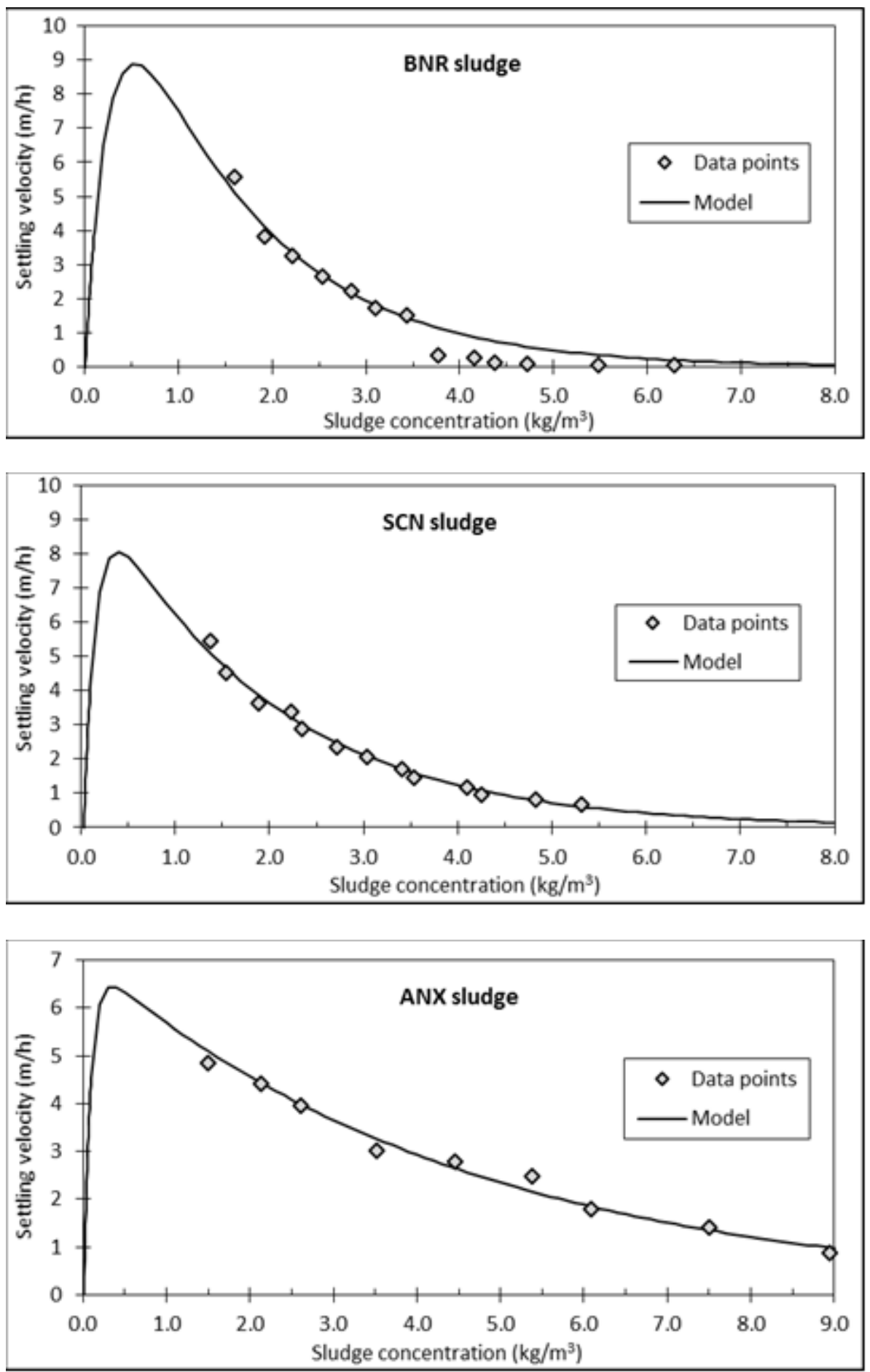

Fig. 4. Best fit of the Takacs model for BNR (top), SNC (middle) and ANX sludge (bottom). 
Table 1. Estimated Takacs model parameters for the BNR, SCN and ANX sludge.

\begin{tabular}{|c|c|c|c|c|}
\hline Parameter & Unit & BNR sludge & SCN sludge & ANX sludge \\
\hline$X$ & $\mathrm{~kg} / \mathrm{m}^{3}$ & $1.6-6.3$ & $1.4-5.3$ & $1.5-8.9$ \\
\hline$v_{s}$ & $\mathrm{~m} / \mathrm{d}$ & $0.04-5.6$ & $0.66-5.5$ & $0.89-4.85$ \\
\hline$v_{0}$ & $\mathrm{~m} / \mathrm{d}$ & 15.5 & 10.5 & 7.08 \\
\hline$r_{h}$ & $\mathrm{~m}^{3} / \mathrm{kg}$ & 0.692 & 0.537 & 0.221 \\
\hline$r_{f}$ & $\mathrm{~m}^{3} / \mathrm{kg}$ & 4.0 & 8.0 & 12 \\
\hline$f_{n s}$ & - & 0.0005 & 0.02 & 0.005 \\
\hline$X_{0}$ & $\mathrm{~kg} / \mathrm{m}^{3}$ & 5.5 & 1.5 & 2.0 \\
\hline
\end{tabular}

The values of the $v_{0}, r_{h}$ and $r_{f}$ parameters were estimated based on the performed series of batch settling test, whereas the values of the $f_{n s}$ and $X_{0}$ parameters were assumed based on the typical values of effluent suspended solids and MLSS in the appropriate reactors (not shown). The values of the $r_{f}$ parameter are initial estimates, as the model is relatively insensitive to this parameter in the sludge concentration range that can be tested in the batch settling tests. Therefore, the final values of the $r_{f}$ parameter, which impacts the predicted settling velocities at low sludge concentrations, need to be established during clarifier model fine tuning based on the data from the real system.

In general, a good fit of the Takacs sedimentation model to the experimental data points of all the three kinds of tested activated sludge was achieved, except for the data points of the BNR sludge with concentration above the $3.5 \mathrm{~kg} / \mathrm{m}^{3}$, which were rejected from model fitting, due to the observed wall effect disturbances mentioned earlier.

The settling properties of the SCN sludge are similar to the BNR sludge, which was to be expected as the SCN reactor is bioaugmented with the BNR sludge to improve the settling characteristics of the otherwise poorly settling nitrifiers dominated activated sludge. However, slightly higher settling velocities were observed at higher concentration, which may be attributed to the high concentration of nitrite in the SNC reactor. Nitrite, especially in its unionized form the free nitrous acid, is a known strong biocidal agent [13], which may selectively inactivate filamentous bacteria which tend to extend from the sludge flocs, thus improving sludge settling.

Sludge from the Anammox reactor, despite the initial seed with the Anammox granular sludge, exhibited flocculent-like behaviour, which may be attributed to the fact the SBR was operated for an extended period with long sedimentation phase (60 min.), which removed a strong factor promoting granulation. Moreover, some amount of flocculent sludge was fed to the Anammox SBR with effluent from the partial nitritation SBR (the first stage of 2-stage deammonification). Presence of nitrifiers in the Anammox reactor may be beneficial, as nitrifiers will remove any dissolved oxygen, which inhibits Anammox bacteria at very low concentration. The visual inspection of the ANX sludge showed that the sludge consisted of small red granules covered with brown flocs, which may explain the flocculent-like behaviour. Nevertheless, the ANX sludge was characterized by a significantly higher settling velocities, especially at higher sludge concentration, compared to typical flocculent sludge (see Fig. 3.). 


\section{Conclusions}

For the purpose of mathematical modelling and simulation of sidestream treatment processes, batch settling tests allow for a proper characterization of sludge settling properties, and the Takacs sedimentation model provides a good prediction of sludge settling behaviour, if the sludge has a flocculent-like nature.

Acknowledgements - The authors gratefully acknowledge co-funding from the National Centre for Research and Development (grant no. PBS2/B9/25/2014) and the Municipal Water and Sewage Company in Wroclaw.

\section{References}

1. Metcalf \& Eddy, Wastewater Engineering: Treatment and Resource Recovery (G. Tchobanoglous, F.L. Burton, H.D. Stensel, ed.), McGraw-Hill Education (2014)

2. Clarifier Design: WEF Manual of Practice No. FD-8, McGraw Hill Professional, 2005

3. J. Makinia, Mathematical modelling and computer simulation of activated sludge systems, London; New York, IWA Publishing (2010)

4. S. Lackner, E.M. Gilbert, S.E. Vlaeminck, A. Joss, H. Horn, M.C.M. van Loosdrecht, Water Res. 55 (2014)

5. W.R. Abma, C.E. Schultz, J.W. Mulder, W.R.L. van der Star, M. Strous, T. Tokutomi, M.C.M. van Loosdrecht, Water Sci.Technol. 55, 8 (2007)

6. A. Nor Anuar, Z. Ujang, M.C.M. van Loosdrecht and M.K. de Kreuk, Water Sci. Technol. 56, 7 (2007)

7. I. Takacs, G. Patry, D. Nolasco, Water Res. 25, 10 (1991)

8. Y.-H. Liu, Y.-L. He, S.-C. Yang, Y.-Z. Li, Biotechnol. Lett. 28 (2006)

9. H-F. Lu, P. Zheng, Q-X. Ji, H-T. Zhang, J-Y. Ji, L. Wang, S. Ding, T-T. Chen, J-Q. Zhang, C-J. Tang, J-W. Chen, Bioresource Technol. 123 (2012)

10. Y. Liu, Z-W. Wang, Y-Q. Liu, L. Qin, J-H. Tay, Biotechnol. Progr. 21 (2005)

11. A. Vanderhasselt, P.A. Vanrolleghem, Water Res. 34, 2 (2000)

12. A.-E. Stricker, I. Takacs, A. Marquot, Water Sci. Technol. 56, 12 (2007)

13. Y. Law, L. Ye, Q. Wang, S. Hu, M. Pijuan, Z. Yuan, Chem. Eng. J. 259 (2015) 